\title{
Elevated plasma hemoglobin in COVID-19-related illnesses: a critical appraisal
}

\author{
Nishant R. Tiwari ${ }^{1}$ (D) Nagnath K. Redewad ${ }^{1}$ - Apurva A. Ketkar ${ }^{1}$. Vivek R. Sharma ${ }^{2}$ \\ Received: 16 August 2020 / Accepted: 21 September 2020 / Published online: 24 September 2020 \\ (C) Springer-Verlag GmbH Germany, part of Springer Nature 2020
}

\section{Dear Editor,}

We read with interest the letter by Lancman et al. [1] describing their study of 38 consecutive coronavirus disease-2019 (COVID-19) patients whom they tested for hemolysis and found that about $80 \%(31 / 38)$ had elevated plasma-free hemoglobin $(\mathrm{Hgb})$ concentration $(>5 \mathrm{mg} / \mathrm{dL}$ ), with highly pathogenic levels (>30 mg/dL) in 24\% (9/38). The authors speculate that the mechanism of intravascular hemolysis may involve viral spike protein interaction with CD-147 on RBCs and that the depletion of nitric oxide (NO), as well as the direct endothelial injury caused by the excess plasma-free Hgb, may contribute to the prothrombotic state seen with severe COVID-19 infection. This is an intriguing observation that may have implications for better understanding the pathophysiology of certain complications of COVID-19 and potentially improving their management. As the authors acknowledge, however, these observations need to be verified by further study. As a start, we believe it is crucial to get more clarity on certain aspects of the data and address potential confounders.

In this study, 14/37 patients received renal replacement therapy (RRT), but it is unclear whether this occurred in patients with all levels of plasma-free Hgb or predominantly those with the highest levels. Both continuous renal replacement therapy (CRRT) and intermittent hemodialysis are known to be associated with intravascular hemolysis by impairing the antioxidant response [2-4], and CRRT has been reported to be a potential confounder in the interpretation of

Nishant R. Tiwari

dr.nishant.tiwari.1996@gmail.com

1 Department of Internal Medicine, Byramjee Jeejeebhoy Government Medical College, Pune, Maharashtra 411001, India

2 Department of Hematology, University of Louisville Hospital, Louisville, KY, USA elevated plasma-free Hgb levels. [2] The authors further state that only "minimal" schistocytosis was noted in $26 \%(10 / 38)$ patients, which is a qualitative measure that can be subjective. Were the nine patients with the highest free Hgb levels in this group? Also, three patients had ADAMTS-13 tests implying some degree of concern for microangiopathic hemolysis. While thrombotic thrombocytopenic purpura was ruled out in these cases due to $>10 \%$ ADAMTS-13 activity, thrombotic microangiopathy (TMA) due to another etiology such as complement dysregulation or infection cannot be ruled out without further information about parameters such as platelet count, coagulation profile, and renal function.

The test for plasma-free $\mathrm{Hgb}$ is another potential confounder. This test is not widely used in clinical care in the USA, and is not available in most labs and can be subject to errors due to artifactual influences. It is unclear whether the authors used enzyme-linked immunosorbent assay (ELISA) or one of the spectrophotometric techniques for this test $[5,6] .4 / 15$ patients in the group of plasma-free $\mathrm{Hgb}>15 \mathrm{mg} / \mathrm{dL}$ had elevated bilirubin. It might be helpful to look at the bilirubin levels of these patients, as elevated bilirubin levels (especially if $>5$ $\mathrm{mg} / \mathrm{dL}$ ) interfere with plasma-free $\mathrm{Hgb}$ measurement. Increased bilirubin concentration is known to cause positive interference during the analysis of plasma-free $\mathrm{Hgb}$ by the spectrophotometric methods. [7] Some laboratories do not even report plasma-free $\mathrm{Hgb}$ in patients with bilirubin $>5$ $\mathrm{mg} / \mathrm{dL}$ as they are often spuriously elevated. [5] In such cases, reporting and trending of oxyhemoglobin is recommended [8].

In essence, the authors have conducted a thoughtful study and raised interesting questions that warrant further scrutiny starting with a stratified analysis of various patient characteristics based on their plasma-free Hgb concentration, which may provide better insight into their data. This becomes particularly important given the potential confounders mentioned above, and they may not be the only ones. Such analysis will help provide the appropriate focus and direction for further study along these lines [9]. 


\section{Compliance with ethical standards}

Conflict of interest The authors declare that they have no conflict of interest.

\section{References}

1. Lancman G, Marcellino BK, Thibaud S, Troy K (2020) Coombsnegative hemolytic anemia and elevated plasma hemoglobin levels in COVID-19. Ann Hematol. Published online:1. https://doi.org/10. 1007/s00277-020-04202-3

2. Lubnow M, Philipp A, Foltan M et al (2014) Technical complications during veno-venous extracorporeal membrane oxygenation and their relevance predicting a system-exchange - retrospective analysis of 265 cases. PLoS One 9(12). https://doi.org/10.1371/journal.pone. 0112316

3. Tharmaraj D, Kerr PG (2017) Haemolysis in haemodialysis. Nephrology. 22(11):838-847. https://doi.org/10.1111/nep.13119

4. Weinstein T, Chagnac A, Korzets A, Boaz M, Ori Y, Herman M, Malachi T, Gafter U (2000) Haemolysis in haemodialysis patients: evidence for impaired defence mechanisms against oxidative stress. Nephrol Dial Transplant. 15(6):883-887. https://doi.org/10.1093/ ndt/15.6.883

5. Fairbanks VF, Ziesmer SC, O'brien PC (1992) Methods for measuring plasma hemoglobin in micromolar concentration compared. Clin Chem 38(1):132-140

6. Adamzik M, Hamburger T, Petrat F, Peters J, de Groot H, Hartmann M (2012) Free hemoglobin concentration in severe sepsis: methods of measurement and prediction of outcome. Crit Care 16(4). https:// doi.org/10.1186/cc11425

7. Wians FH, Miller CL, Heald JI, Clark H (1988) Evaluation of a direct spectrophotometric procedure for quantitating plasma hemoglobin. Lab Med. 19(3):151-155. https://doi.org/10.1093/labmed/19.3.151

8. PLHBB - Clinical: plasma free hemoglobin, plasma. Accessed Aug 12, 2020. https://www.mayocliniclabs.com/test-catalog/ Clinical+and+Interpretive/9096

9. Jager KJ, Zoccali C, MacLeod A, Dekker FW (2008) Confounding: what it is and how to deal with it. Kidney Int. 73(3):256-260. https:// doi.org/10.1038/sj.ki.5002650

Publisher's note Springer Nature remains neutral with regard to jurisdictional claims in published maps and institutional affiliations. 